\title{
Human leptospirosis cases and the prevalence of rats harbouring Leptospira interrogans in urban areas of Tokyo, Japan
}

\begin{abstract}
Correspondence
Nobuo Koizumi

nkoizumi@nih.go.jp
\end{abstract}

Received 1 April 2009

Accepted 28 May 2009

\author{
Nobuo Koizumi, ${ }^{1}$ Maki Muto, ${ }^{1}$ Tsutomu Tanikawa, ${ }^{2}$ Hiroshi Mizutani, ${ }^{3} \dagger$ \\ Yoshiko Sohmura, ${ }^{3}$ Eiji Hayashi, ${ }^{4} \ddagger$ Nobuaki Akao, ${ }^{4}$ Mayu Hoshino, ${ }^{1} \S$ \\ Hiroki Kawabata ${ }^{1}$ and Haruo Watanabe ${ }^{5}$
${ }^{1}$ Department of Bacteriology, National Institute of Infectious Diseases, 1-23-1 Toyama, Shinjuku- ku, Tokyo 162-8640, Japan
${ }^{2}$ Ikari Corporation, 579 Chibadera, Chuo-ku, Chiba 260-0844, Japan
${ }^{3}$ Tokyo Metropolitan Animal Care and Consultation Center, 3-2-1 Jonanjima, Ohta-ku, Tokyo 143- 0002, Japan
${ }^{4}$ Section of Environmental Parasitology, Tokyo Medical and Dental University, 1-5-45 Yushima, Bunkyo-ku, Tokyo 113-8510, Japan \\ ${ }^{5}$ National Institute of Infectious Diseases, 1-23-1 Toyama, Shinjuku-ku, Tokyo 162-8640, Japan
}

Thirteen patients with leptospirosis were identified, as confirmed by laboratory analysis during the last 5 years in our laboratory, who came from urban areas of Tokyo, Japan. All of the patients came into contact with rats before the onset of illness. Seventeen per cent of Norway rats captured in the inner cities of Tokyo carried leptospires in their kidneys. Most of these rat isolates were Leptospira interrogans serovar Copenhageni/lcterohaemorrhagiae. Antibodies against these serovars and their DNA were detected in the patients. This suggests that rats are important reservoirs of leptospirosis, and that rat-borne leptospires occur in urban areas of Tokyo.

\section{INTRODUCTION}

Leptospirosis is caused by infection with pathogenic Leptospira. It is a globally important zoonotic disease that affects humans in rural and urban settings, in both industrialized and developing countries (Bharti et al., 2003; Levett, 2001; McBride et al., 2005). Transmission of Leptospira pathogens to humans occurs mainly through indirect contact with water or soil contaminated by the urine of infected animals (Faine et al., 1999). Leptospirosis has become an important public health problem in Asia and Latin America. In these tropical areas, large outbreaks of leptospirosis are most likely to occur after floods,

tPresent address: Tokyo Metropolitan Shibaura Meat Sanitary Inspection Station, 2-7-19 Konan, Minato-ku, Tokyo 108-0075, Japan.

¥Present address: Togane Hospital, 1229 Daikata, Togane, Chiba 2838588, Japan.

§Present address: Horticultural Institute, Ibaraki Agricultural Center, 3165-1 Ago, Kasama, Ibaraki 3165-1, Japan.

Abbreviation: MAT, microscopic agglutination test.

The GenBank/EMBL/DDBJ accession numbers for the flaB sequences of rat isolates and patient samples are AB454100-AB454125.

A table of detection test data and a figure of PFGE results are available as supplementary data with the online version of this paper. hurricanes or other disasters. Leptospirosis has also become an urban problem in developing countries. Outbreaks occur in poor urban slum communities during seasonal periods of heavy rainfall (Johnson et al., 2004; Ko et al., 1999; LaRocque et al., 2005). The risk of infection in urban inhabitants is not limited to developing countries because the importance of urban leptospirosis has already been recognized in inner-city populations of the USA (Vinetz et al., 1996). In the present study, we report the presence of leptospirosis and rat reservoirs of leptospires in urban areas of Tokyo, Japan.

\section{METHODS}

Serodiagnosis of patients with clinically suspected leptospirosis. The microscopic agglutination test (MAT) for detection of antiLeptospira antibodies in patient serum samples was performed (Faine et al., 1999) using a battery of reference strains described previously (Koizumi et al., 2008). These reference strains were cultivated in liquid modified Korthof's medium with $10 \%$ rabbit serum at $30{ }^{\circ} \mathrm{C}$ (Faine et al., 1999). Detection of IgM was also carried out by IgM dot enzyme-linked immunoassay (Dip-S-Ticks; PanBio) for cases 6 and 8 (Supplementary Table S1 available with the online journal).

Isolation of leptospires from rats. Norway rats (Rattus norvegicus) were captured using live traps at 14 locations in urban areas of Tokyo from 2002 to 2007. For the isolation of leptospires, rat kidneys were inoculated into medium and cultivated as described above. 
PCR. DNA was extracted from Leptospira isolates, and the blood and urine samples of patients, using a DNeasy tissue kit (Qiagen). Extracted DNAs were subjected to PCR to detect the Leptospira flaB gene (flaB-PCR; Kawabata et al., 2001; Koizumi et al., 2003). Sequencing of amplicons was performed by the dideoxynucleotide chain-termination method using a BigDye terminator v1.1 cycle sequencing kit (Applied Biosystems).

Identification of serogroups of rat isolates. The serogroups of the isolates were identified by MAT using a panel of anti-Leptospira rabbit sera for serovars Australis, Autumnalis, Canicola, Copenhageni, Hebdomadis and Icterohaemorrhagiae, which are present in the main island of Japan.

PFGE. PFGE of rat isolates was carried out as described previously (Koizumi et al., 2009).

\section{RESULTS AND DISCUSSION}

\section{Human leptospirosis cases in urban areas of Tokyo}

In the last 5 years (from the first case on 4 September 2003 to the last on 18 September 2008), we carried out laboratory examinations for leptospirosis for 55 cases. According to their physicians in Tokyo, the symptoms in these patients matched those of leptospirosis. A total of 16 cases were revealed to be positive for leptospirosis during the period of the study; 13 were from Tokyo (Table 1, Supplementary Table S1 available with the online journal) and the other 3 cases were from Bali (Indonesia), Borneo (Malaysia) and Fiji (data not shown). Among the 13 cases in Tokyo, 12 patients were definitively diagnosed by MAT (fourfold increase in antibody titre between acute and convalescent serum samples or reciprocal MAT titre of at least 400 in a single serum sample), including 4 patients who were also positive for the leptospiral flaB gene by PCR using urine or blood specimens. One probable case was demonstrated by anti-leptospiral IgM and a MAT titre of $1: 160$. All patients were hospitalized with severe manifestations, such as acute renal failure and jaundice, indicating that they had contracted Weil's disease (a severe type of leptospirosis). All patients declared that they had come into contact with rats (Table 1). Two patients (nos 1 and 2) worked at a place where they came in contact with rats, and rats were frequently found in the houses or stores of other patients (nos 3-13). The patients neither performed agricultural work nor undertook recreational activity in an endemic area, nor were they exposed to possible reservoir animals other than rats, which are generally considered as high risk behaviours. Among the 39 leptospirosis-negative cases, only 4 patients came in contact with rats ( 1 patient was a construction worker, and rats were seen at the houses of the other 3 patients). This indicated that the ratio of contact with rats among leptospirosis-positive cases was significantly higher than that among leptospirosis-negative cases in urban areas of Tokyo (Fisher's exact test, $P<0.01$ ). Since leptospirosis became a reportable disease in Japan (from November 2003), another laboratory-confirmed case other than the 13 cases mentioned above was reported from a regional medical centre in Tokyo in September 2006. The patient saw rats at his restaurant (T. Iida, personal communication).

\section{Isolation and characterization of Leptospira interrogans from Norway rats captured in urban areas of Tokyo}

We captured 127 Norway rats ( $R$. norvegicus) at 14 locations in urban areas of Tokyo from 2002 to 2007. Leptospires were isolated from 22 of the 127 rats from 6 of

Table 1. Human leptospirosis in urban areas of Tokyo diagnosed in our laboratory from 2003 to 2008

\begin{tabular}{|c|c|c|c|c|c|}
\hline $\begin{array}{l}\text { Patient } \\
\text { no. }\end{array}$ & Year & Sex & Age (years) & Occupation & Association with rats \\
\hline 1 & 2003 & M & 66 & Construction worker & Probable environmental contamination with rat urine \\
\hline 3 & 2005 & $\mathrm{~F}$ & 53 & Housewife & Rats appeared frequently in patient's house \\
\hline 4 & 2005 & M & 65 & Butcher & $\begin{array}{l}\text { Patient cleaned the urine and faeces of rats in his store without wearing } \\
\text { gloves }\end{array}$ \\
\hline 6 & 2006 & M & 62 & Unknown & Rats appeared frequently in patient's house \\
\hline 7 & 2006 & M & 54 & Fish dealer & $\begin{array}{l}\text { Patient cleaned the urine and faeces of rats in his store without wearing } \\
\text { gloves }\end{array}$ \\
\hline 8 & 2007 & M & 51 & Day worker & $\begin{array}{l}\text { Rats appeared frequently in patient's house (he had been bitten by a rat } \\
\text { at his house) }\end{array}$ \\
\hline 9 & 2007 & $\mathrm{~F}$ & 57 & Restaurant worker & Rats appeared frequently in patient's restaurant \\
\hline
\end{tabular}

F, Female; M, male. 
the 14 places (Table 2). Nucleotide sequences of the partial flaB gene from 18 rats captured at locations F, G, H, K and $M$ were identical (GenBank accession numbers AB454100$\mathrm{AB} 454117)$ and those from 4 rats at location $\mathrm{A}$ (the flaB sequences were identical among the four; GenBank accession numbers AB454118-AB454121) were different in six bases from those described above. The sequences from the 18 rats were identical to those of the reference strains of $L$. interrogans serovar Copenhageni and Icterohaemorrhagiae, suggesting that all the isolates were $L$. interrogans. These isolates reacted equally with antiCopenhageni and anti-Icterohaemorrhagiae sera, but not with the other sera (data not shown). The NotI restriction patterns of the genomes of the isolates from the 18 rats were identical on PFGE not only to each other, but also to the reference strains of serovars Copenhageni and Icterohaemorrhagiae (Supplementary Fig. S1 available with the online journal). It has been determined by PFGE that the genomes of leptospiral serovars have been remarkably conserved over time and across a wide geographical distribution (Herrmann et al., 1991, 1992). Most (but not all) serovars give unique patterns on PFGE carried out using the restriction enzyme NotI, although the $L$. interrogans serovars Copenhageni and Icterohaemorrhagiae are indistinguishable. These two serovars are also very difficult to distinguish by serological methods (Kobayashi $e t$ al., 1984). These results indicate that isolates from the 18 rats belonged to $L$. interrogans serovar Copenhageni or Icterohaemorrhagiae, which are known to frequently cause Weil's disease in Japan and other countries. We could not carry out MAT for serogroup identification and PFGE on the four isolates at location A due to poor growth.

Table 2. Isolation of leptospires from rats captured in urban areas of Tokyo

\begin{tabular}{|lcc|}
\hline Location & No. of rats captured & $\begin{array}{c}\text { No. of rats from } \\
\text { which Leptospira } \\
\text { was isolated (\%) }\end{array}$ \\
\hline A - park & 15 & $4(27)$ \\
B - park & 2 & 0 \\
C - street & 4 & 0 \\
D - street & 8 & 0 \\
E - building & 12 & 0 \\
F - street & 29 & $12(41)$ \\
G - street & 1 & $1(100)$ \\
H - garden (house & 4 & $3(75)$ \\
I - park & 1 & 0 \\
J - street & 12 & 0 \\
K - street & 13 & $1(8)$ \\
L - street & 5 & 0 \\
M - store & 2 & $1(50)$ \\
N - street & 19 & 0 \\
Total & 127 & $22(17)$ \\
& & \\
\hline
\end{tabular}

${ }^{\star}$ Location $\mathrm{M}$ was a store in which patient 7 used to work; other locations are not related to the putative exposure sites of the patients.

\section{Conclusion}

In 5 of the 13 human leptospirosis cases (cases 1-3, 6 and 7), the patients were infected with serovar Copenhageni or Icterohaemorrhagiae as shown by serological and PCRbased evidence (Supplementary Table S1 available with the online journal). Cross-agglutination and even paradoxical reactions are observed in MAT, but the existence of antibodies against serovars Copenhageni and Icterohaemorrhagiae in all other serum samples suggests the possibility of infection with these serovars (Supplementary Table S1 available with the online journal). Nucleotide sequences of the partial flaB gene from urine and blood (patients 1,2,3 and 7; GenBank accession numbers AB454122-AB454125) were identical to those from the rat isolates. In particular, Leptospira was isolated from a rat captured at the store where patient 7 previously worked. Although there is a possibility of recall bias, all the patients said they had rat contact (Table 1). Dogs and cats may also serve as reservoir hosts in urban settings. We attempted to isolate leptospires from the kidney tissues of stray or abandoned dogs and cats in Tokyo (304 dogs and 77 cats), but Leptospira was not obtained. These results strongly suggest that the patients contracted leptospirosis (Weil's disease) from rats in urban areas of Tokyo, though the possibility of involvement of other reservoir animals cannot be excluded.

Outbreaks of leptospirosis are recognized through occupational exposure, such as rice farming and other agricultural activities in rural areas of the tropics (Tangkanakul et al., 2000). Leptospirosis has also become a health problem in urban slums in developing countries (Johnson et al., 2004; Ko et al., 1999; LaRocque et al., 2005). In 'developed countries', recreational activities have recently been identified as a significant risk factor for leptospirosis (Bharti et al., 2003; Levett, 2001; McBride et al., 2005). The present study suggests that humans could contract leptospirosis through occupational exposure or exposure during activities of daily life in environments contaminated with rat urine containing leptospires in urban areas in Tokyo. Leptospirosis constitutes one of the neglected diseases in Japan except for Okinawa Prefecture (Nakamura et al., 2006; Narita et al., 2005). This is one of the reasons why few cases have been identified over the 5 year period despite the high carriage of leptospires in rats in Tokyo. A high prevalence of Leptospira spp. in Norway rats from urban settings has also been reported from temperate and tropical endemic countries, but human leptospirosis in urban areas is underreported even in an endemic country (Ariyapruchya et al., 2003; Demers et al., 1985; Doungchawee et al., 2005; Easterbrook et al., 2007; Krøjgaard et al., 2009). Physicians and public health authorities should, therefore, be aware of the severe risk of contracting leptospirosis associated with rats in urban areas.

\section{ACKNOWLEDGEMENTS}

We are grateful to $\mathrm{H}$. Obe and $\mathrm{M}$. Uchida for their technical assistance. This work was supported in part by a Health Sciences 
Research Grant-in-Aid for Emerging and Re-emerging Infectious Diseases (H13-Shinkou-4, H16-Shinkou-Ippan-033 and H18Shinkou-8) from the Ministry of Health, Labour and Welfare of Japan.

\section{REFERENCES}

Ariyapruchya, B., Sungkanuparph, S. \& Dumrongkitchaiporn, S. (2003). Clinical presentation and medical complication in 59 cases of laboratory-confirmed leptospirosis in Bangkok. Southeast Asian J Trop Med Public Health 34, 159-164.

Bharti, A. R., Nally, J. E., Ricaldi, J. N., Matthias, M. A., Diaz, M. M., Lovett, M. A., Levett, P. N., Gilman, R. H., Willig, M. R. \& other authors (2003). Leptospirosis: a zoonotic disease of global importance. Lancet Infect Dis 3, 757-771.

Demers, R. Y., Frank, R., Demers, P. \& Clay, M. (1985). Leptospiral exposure in Detroit rodent control workers. Am J Public Health 75, 1090-1091.

Doungchawee, G., Phulsuksombat, D., Naigowit, P., Khoaprasert, Y., Sangjun, N., Kongtim, S. \& Smythe, L. (2005). Survey of leptospirosis of small mammals in Thailand. Southeast Asian J Trop Med Public Health 36, 1516-1522.

Easterbrook, J. D., Kaplan, J. B., Vanasco, N. B., Reeves, W. K., Purcell, R. H., Kosoy, M. Y., Glass, G. E., Watson, J. \& Klein, S. L. (2007). A survey of zoonotic pathogens carried by Norway rats in Baltimore, Maryland, USA. Epidemiol Infect 135, 1192-1199.

Faine, S., Adler, B., Bolin, C. \& Perolat, P. (1999). Leptospira and Leptospirosis, 2nd edn. Melbourne: MediSci.

Herrmann, J. L., Baril, C., Bellenger, E., Perolat, P., Baranton, G. \& Saint Girons, I. (1991). Genome conservation in isolates of Leptospira interrogans. J Bacteriol 173, 7582-7588.

Herrmann, J. L., Bellenger, E., Perolat, P., Baranton, G. \& Saint Girons, I. (1992). Pulsed-field gel electrophoresis of NotI digests of leptospiral DNA: a new rapid method of serovar identification. J Clin Microbiol 30, 1696-1702.

Johnson, M. A. S., Smith, H., Joseph, P., Gilman, R. H., Bautista, C. T., Campos, K. J., Cespedes, M., Klatsky, P., Vidal, C. \& other authors (2004). Environmental exposure and leptospirosis, Peru. Emerg Infect Dis 10, 1016-1022.

Kawabata, H., Dancel, L. A., Villanueva, S. Y., Yanagihara, Y., Koizumi, N. \& Watanabe, H. (2001). flaB-polymerase chain reaction (flaB-PCR) and its restriction fragment length polymorphism (RFLP) analysis are an efficient tool for detection and identification of Leptospira spp. Microbiol Immunol 45, 491-496.

Ko, A. I., Galvão Reis, M., Ribeiro Dourado, C. M., Johnson, W. D., Jr \& Riley, L. W. (1999). Urban epidemic of severe leptospirosis in Brazil. Lancet 354, 820-825.

Kobayashi, Y., Tamai, T., Oyama, T., Hasegawa, H., Sada, E., Kusaba, T. \& Hamaji, M. (1984). Characterization of monoclonal antibodies against etiological agents of Weil's disease. Microbiol Immunol 28, 359-370.

Koizumi, N., Watanabe, H., Umezawa, K., liduka, T. \& Inokuchi, S. (2003). A case of leptospirosis diagnosed early by flaB-PCR. Kansenshogaku Zasshi 77, 627-630 (in Japanese).

Koizumi, N., Muto, M., Yamamoto, S., Baba, Y., Kudo, M., Tamae, Y., Shimomura, K., Takatori, I., Iwakiri, A. \& other authors (2008). Investigation of reservoir animals of Leptospira in the northern part of Miyazaki prefecture. Jpn J Infect Dis 61, 465-468.

Koizumi, N., Uchida, M., Makino, T., Taguri, T., Kuroki, T., Muto, M., Kato, Y. \& Watanabe, H. (2009). Isolation and characterization of Leptospira spp. from raccoons in Japan. J Vet Med Sci 71, 425-429.

Krøjgaard, L. H., Villumsen, S., Markussen, M. D. K., Jensen, J. S., Leirs, H. \& Heiberg, A.-C. (2009). High prevalence of Leptospira spp. in sewer rats (Rattus norvegicus). Epidemiol Infect (in press). doi:10.1017/S0950268809002647

LaRocque, R. C., Breiman, R. F., Ari, M. D., Morey, R. E., Janan, F. A., Hayes, J. M., Hossain, M. A., Brooks, W. A. \& Levett, P. N. (2005). Leptospirosis during dengue outbreak, Bangladesh. Emerg Infect Dis 11, 766-769.

Levett, P. N. (2001). Leptospirosis. Clin Microbiol Rev 14, 296-326.

McBride, A. J. L., Athanazio, D. A., Reis, M. G. \& Ko, A. I. (2005). Leptospirosis. Curr Opin Infect Dis 18, 376-386.

Nakamura, M., Taira, K., Itokazu, K., Kudaka, J., Asato, R., Kise, T. \& Koizumi, N. (2006). Sporadic cases and an outbreak of leptospirosis probably associated with recreational activities in rivers in the northern part of Okinawa Main Island. J Vet Med Sci 68, 83-85.

Narita, M., Fujitani, S., Haake, D. A. \& Paterson, D. L. (2005). Leptospirosis after recreational exposure to water in the Yaeyama Islands, Japan. Am J Trop Med Hyg 73, 652-656.

Tangkanakul, W., Tharmaphornpil, P., Plikaytis, B. D., Bragg, S., Poonsuksombat, D., Choomkasien, P., Kingnate, D. \& Ashford, D. A. (2000). Risk factors associated with leptospirosis in northeastern Thailand, 1998. Am J Trop Med Hyg 63, 204-208.

Vinetz, J. M., Glass, G. E., Flexner, C. E., Mueller, P. \& Kaslow, D. C. (1996). Sporadic urban leptospirosis. Ann Intern Med 125, 794-798. 